\title{
EDUCAÇÃO FÍSICA NA EDUCAÇÃO DE JOVENS E ADULTOS: DESAFIANDO OS DOCENTES
}

\author{
Adenir Machado de Freitas ${ }^{1}$ \\ Derli Juliano Neuenfeldt ${ }^{2}$
}

\begin{abstract}
Resumo: Na Educação de Jovens e Adultos (EJA), há uma relação entre educação e trabalho. Os discentes são trabalhadores, jovens que buscam sua primeira oportunidade de emprego, aqueles que já frequentaram a escola e buscam regressar pela necessidade de uma melhor escolaridade, uma exigência do mercado de trabalho. Esse contexto desafia os professores de Educaçáo Física escolar em suas práticas pedagógicas. Assim, este estudo teve por objetivo investigar dificuldades e aspectos positivos percebidos por professores de Educaçáo Física da rede pública de ensino de um município do Vale do Taquari/RS, ao ministrarem aulas para alunos da EJA. A pesquisa, que se caracteriza como qualitativa, entrevistou quatro professores de Educação Física. Com relação às dificuldades, uma delas é que os alunos chegam exaustos devido ao trabalho. Outra questão que interfere nas aulas são os problemas sociais dos alunos que afetam a estrutura familiar. Ainda, uma terceira refere-se à diferença de faixa etária. A idade dos alunos varia entre 15 e 62 anos, o que dificulta a proposta das aulas. Quanto aos aspectos positivos, os professores comentam que a Educação Física, ao ensinar sobre as práticas corporais, contribui para conhecerem melhor o próprio corpo. Apesar das dificuldades, os professores contam com total apoio da direção de suas escolas.
\end{abstract}

Palavras-chave: Educação Física, Educação de Jovens e Adultos, Escola.

\section{PHYSICAL EDUCATION IN YOUTH AND ADULT EDUCATION: CHALLENGING TEACHERS}

\begin{abstract}
Youth and Adult Education (EJA) has a relationship between education and work. The students are workers, young people looking for their first job opportunity or those who have already gone to school and look to return due to the fact that they need better schooling, normally required for the job market. As a result, this context challenges the Physical Education teachers in their pedagogical practices. Thus, this study aimed investigate public Physical Education teachers'
\end{abstract}

1 Graduado em Educação Física - Licenciatura pela Universidade do Vale do Taquari - Univates.

2 Doutorado em Ciências: Ambiente e Desenvolvimento pela Universidade do Vale do Taquari Univates. Prof. do PPGEnsino e dos cursos de graduação em Educação Física da Univates. 
difficulties and positive aspects perceived in a city in the Valley of Taquari/RS in the teaching of EJA students. The research is characterized as qualitative and used interviews with four Physical Education teachers. In relation to the difficulties faced, one of them is that the students arrive exhausted from work. Another aspect that interferes in lessons are the students' social classes that affect family structures. Still, a third refers to the difference in age group. The students are between 15 and 62 years old, complicating class lessons. As for the positive aspects, the teachers discuss that Physical Education contributes as it teaches the corporal practices to better understand the body. Despite the difficulties, the teachers have total support from their schools' administration.

Keywords: Physical Education, Youth and Adult Education, School.

\section{INTRODUÇÃO}

Esse estudo trata de uma pesquisa que aborda as aulas de Educação Física na Educação de Jovens e Adultos (EJA) em escolas de um município do Vale do Taquari/RS/Brasil. O interesse pelo tema emergiu das inquietaçóes provocadas pela experiência docente de um dos autores, ao realizar, no segundo semestre de 2018, o Estágio Supervisionado II - Anos Finais do Ensino Fundamental, componente obrigatório do curso de Educação Física - Licenciatura da Universidade do Vale do Taquari - Univates.

A EJA é uma modalidade amparada pela Lei n. ${ }^{\circ} 13.632$ de 2018, que alterou a redação da Lei de Diretrizes e Bases da Educação Nacional n. ${ }^{0} 9.394$ de 1996 (BRASIL, 1996), passando a constar no Art. 37 a seguinte redação: "A educação de jovens e adultos será destinada àqueles que não tiveram acesso ou continuidade de estudos nos ensinos fundamental e médio na idade própria e constituirá instrumento para educação e aprendizagem ao longo da vida" (BRASIL, 2018, texto digital). Em 2021, a Resolução n. o 1 instituiu as diretrizes de alinhamento da EJA em relação à Política Nacional de Alfabetização, a Base Nacional Comum Curricular e a EJA a distância (BRASIL, 2021).

Historicamente, a partir da implantação definitiva do regime de séries adotado na reforma de 1931 para o ensino secundário, ao estabelecer a sinonimização entre faixa etária apropriada, seriação e ensino regular, abre-se o caminho para uma oposiçáo dual entre o regular e o que se chamaria supletivo. A avaliaçáo do processo de ensino e aprendizagem passou a ser por meio de exames, provas, bem como passou a determinar a passagem para a série seguinte (BRASIL 2000).

À medida que o acesso à Educação era elitizado, excluindo a classe trabalhadora e economicamente desfavorecida, cresce a preocupação com a EJA, reconhecendo o direito de todos à Educaçáo. Já "a Constituição de 1934 reconheceu, pela primeira vez em caráter nacional, a educação como direito de todos e (que ela) deve ser ministrada pela família e pelos poderes públicos (art. 149)" (BRASIL, 2000, p. 17).

$\mathrm{Na}$ primeira metade do século XX, de acordo com Souza (2012), os principais integrantes da Educação de Adultos eram migrantes de várias localidades da zona rural brasileira. Naquela época, existiam poucas escolas no campo e, ideologicamente, o trabalhador rural náo precisava de estudo para trabalhar com a "enxada". A educação escolar era praticamente inviável para filhos de trabalhadores 
e pessoas com menos poder aquisitivo, pois tinham que trabalhar para elevar a renda familiar.

Porém, o analfabetismo passou a ser entendido como uma característica de subdesenvolvimento do país. Por isso, as autoridades políticas passaram a dedicar sua atenção a esses sujeitos, com o objetivo de alfabetizá-los (SOUZA, 2012). O Governo Federal brasileiro, no século XX, visando alterar esse quadro, desenvolveu várias formas de ensino com foco na população não alfabetizada, sendo uma das mais conhecidas o Movimento Brasileiro de Alfabetização (Mobral), que foi instituído através da Lei n. ${ }^{\circ}$ 5.379/1967, com o objetivo de extinguir o analfabetismo do país, que, na década de 60 , contava com uma população de 15.964 .000 analfabetos. O Mobral existiu durante o regime militar, porém, devido à falta de planejamento, não obteve êxito na alfabetização de milhares de jovens e adultos (LAFFIN, 2011).

Cabe destacar que a década de 60 do século passado foi um marco para o início da Educação de Adultos. A industrialização e a urbanização impulsionaram o Brasil no sentido de enfatizar a educação, que se tornou um requisito necessário para a população conseguir inserir-se no mercado de trabalho. Contudo, como menciona Souza (2012), não podemos deixar de lembrar educadores importantes como Paulo Freire, que lutou pela educação popular não apenas com a finalidade de capacitar máo de obra, mas com o intuito de formar cidadãos capazes de reivindicar seus direitos sociais.

O ensino supletivo, com a Lei n. ${ }^{\circ}$ 5.692/71, ganhou capítulo próprio com cinco artigos. Um deles dizia que este ensino se destinava a 'suprir a escolarização regular para adolescentes e adultos, que não a tinham seguido ou concluído na idade própria'. Este ensino podia, então, abranger o processo de alfabetização, a aprendizagem, a qualificação, algumas disciplinas e também atualização. Os cursos poderiam acontecer via ensino a distância, por correspondência ou por outros meios adequados. Os cursos e os exames seriam organizados dentro dos sistemas estaduais de acordo com seus respectivos Conselhos de Educaçáo (BRASIL, 2000, p. 21).

Em 1988, a Constituição Federal do Brasil incorporou como princípio que toda e qualquer educaçáo deveria visar o pleno desenvolvimento da pessoa, seu preparo para o exercício da cidadania e sua qualificação para o trabalho. A Educação de Jovens e Adultos torna-se uma modalidade estratégica no sentido da igualdade de acesso à educação como bem social. Dessa forma, apesar das mudanças de governo, a EJA se mantém até hoje, contemplando também jovens que não conseguem concluir os estudos no período adequado. Entre as açôes mais recentes do governo brasileiro, Laffin (2011) menciona:

A principal medida foi buscar a articulação política para atender as demandas da educação continuada, com a criação dentro da estrutura do Ministério da Educaçáo, Secretaria de Educação Continuada Alfabetização e Diversidade (SECAD), foi efetivada em julho de 2004, atendendo nesta pasta temas de alfabetização, educação de jovens e adultos, educação do campo, educação ambiental, educação escolar indígena e diversidade étnico racial (LAFFIN, 2011, p. 79). 
Além da SECAD, o governo brasileiro passa a garantir através da Secretaria de Educação Profissional e Tecnológica (SETEC), o direito e o acesso de jovens e adultos à rede federal de ensino, até então ausente, isto é, ao atendimento desta demanda na maioria dos Estados, através do Programa de Integração da Educação com a Educação Básica na Modalidade de Educação de Jovens e Adultos (PROEJA).

O Programa de Integração da Educação Profissional com a Educação Básica na Modalidade de Educação de Jovens e Adultos, originário do decreto n. ${ }^{\circ}$ 5.478, de 24/06/2005 (PROEJA), depois substituído pelo decreto no 5.840, de 2006, visa a formação continuada de trabalhadores e educaçáo profissional técnica de nível médio que tem por objetivo oferecer a oportunidade da conclusão da educação básica, juntamente com a formação profissional àqueles que não tiveram acesso ao ensino médio na idade regular (SOUZA, 2012, p. 171).

Atualmente, a relação entre educação e trabalho ainda permeia a EJA. Os discentes são trabalhadores ou até mesmo jovens que buscam sua primeira oportunidade de emprego ou aqueles que já frequentaram a escola e buscam regressar pela necessidade de uma melhor escolaridade e, principalmente, pelas exigências do mercado de trabalho. Contudo, Günther et al. (2013) destacam que a EJA vem passando por um processo de juvenilizaçáo, ou seja, cada vez mais adolescentes se fazem presentes. "Aos poucos, a EJA vai perdendo sua característica inicial de atender jovens e adultos trabalhadores para tornar-se um 'atalho' para a conclusão do Ensino Fundamental. Esse é um fenômeno que vem se acentuando nos últimos anos e, ao que parece, mais intenso na EJA de Ensino Fundamental" (GÜNTHER et al., 2013, p. 17).

A partir dessa contextualizaçáo, nos remetemos ao tema desse artigo: o ensino da Educação Física escolar na EJA. A Educação Física é o componente curricular "que tematiza as práticas corporais em suas diversas formas de codificação e de significação social, entendidas como manifestaçóes das possibilidades expressivas dos sujeitos, produzidas por diversos grupos sociais no decorrer da história" (BRASIL, 2017, p. 211). A Educação Física é componente obrigatório em toda a Educação Básica e nas diferentes modalidades de ensino. $\mathrm{Na}$ Lei no 10.793 , consta:

$\$ 3^{0}$ A educação física, integrada à proposta pedagógica da escola, é componente curricular obrigatório da educação básica, sendo sua prática facultativa ao aluno:

I - que cumpra jornada de trabalho igual ou superior a seis horas;

II - maior de trinta anos de idade;

III - que estiver prestando serviço militar inicial ou que, em situação similar, estiver obrigado à prática da educação física;

IV - amparado pelo Decreto-Lei no 1.044, de 21 de outubro de 1969;

$\mathrm{V}-(\mathrm{VETADO})$

VI - que tenha prole (BRASIL, 2003, texto digital).

Contudo, a lei acima mencionada possibilita a facultatividade aos alunos, ação conhecida como pedido de dispensa, que se acentua na EJA, pelo fato de a maioria 
dos alunos serem trabalhadores e/ou terem mais de 30 anos. Essas peculiaridades afetam diretamente o ensino da Educação Física.

Este artigo teve como objetivo investigar dificuldades e aspectos positivos percebidos por professores de Educaçáo Física da rede pública de ensino de um município do Vale do Taquari/RS, ao ministrarem aulas para alunos da EJA.

Portanto, este artigo se justifica em função da necessidade de trazer subsídios para compreendermos como a Educação Física está sendo desenvolvida na EJA, bem como para refletirmos sobre a necessidade de olharmos para as particularidades desses alunos, que têm direito a um ensino de qualidade.

\section{PROCEDIMENTOS METODOLÓGICOS}

\section{Característica da Pesquisa}

O presente estudo é uma pesquisa qualitativa. Para Bogdan e Biklen (1994), a abordagem qualitativa de investigação exige que o mundo seja examinado tendo presente a ideia de que nada é trivial, de que tudo tem potencial para constituir uma pista que permita compreender melhor nosso objeto de estudo. Ela volta-se para o modo como diferentes pessoas dão sentido às suas vidas e possibilita uma relação de diálogo entre investigador e sujeitos investigados. Trivińos (1987, p.128) destaca que a pesquisa qualitativa é essencialmente descritiva, pois "as descriçôes dos fenômenos estão impregnadas de significados que o ambiente lhe outorga e, como aquelas são produto de uma visão subjetiva, rejeita toda a expressão quantitativa, numérica, toda medida”.

\section{Contexto e sujeitos do Estudo}

Essa pesquisa foi desenvolvida com docentes de Educação Física de quatro escolas municipais e estaduais que ofertam a modalidade EJA, de um município do Vale do Taquari/RS/BRA. Participaram quatro professores, dois da rede de ensino estadual e dois da rede de ensino municipal, que ministram aulas nas etapas da EJA, correspondentes aos Anos Finais do Ensino Fundamental.

A pesquisa foi autorizada mediante carta de anuência assinada pela Secretaria de Educaçáo do município e outra pela 3. ${ }^{a}$ Coordenadoria Regional de Educaçáo (CRE), situada em Estrela, que responde pela rede estadual das escolas do Vale do Taquari/RS.

\section{Instrumentos e procedimentos de coleta de informaçóes}

A coleta de informaçóes ocorreu por meio de entrevista semiestruturada. De acordo com Negrine (1999), ela é semiestruturada, quando o instrumento de coleta é pensado para obter informaçóes de questóes concretas, previamente definidas pelo pesquisador, mas, ao mesmo tempo, permite que se realizem exploraçóes não 
previstas, dando liberdade ao entrevistado para dissertar sobre o tema, abordando aspectos que considera relevantes sobre o que pensa.

Os entrevistados foram questionados a respeito do cotidiano das aulas de Educação Física na Educação Física escolar, das principais dificuldades encontradas na docência e aspectos considerados positivos nessa forma de oferta de ensino. A partir dessas questóes norteadoras, estabeleceu-se um diálogo que permitiu que novas temáticas emergissem.

As entrevistas foram agendadas previamente de acordo com a disponibilidade de horário dos participantes. Elas foram gravadas, transcritas e disponibilizadas para o entrevistado para que pudesse lê-las e ratificá-las, ou, caso quisesse, modificar o texto transcrito. Após serem revisadas e aprovadas, foram usadas no estudo. Esses procedimentos foram adotados com todos os entrevistados da pesquisa.

\section{Análise das Informaçóes}

Quanto à análise das informaçóes, optou-se pela análise textual discursiva, estruturando uma categoria emergente. A categorização busca novos entendimentos, num movimento construído numa ordem diferente da original; por isso, esse processo precisa da definição e da explicaçáo dos núcleos das categorias, para formar um entrelaçamento na superposição das fronteiras e constituir um todo integrado (MORAES; GALIAZZI, 2016). A categoria estabelecida emergiu do conjunto de opiniōes e representaçóes sociais sobre o tema investigado, sendo ela: dificuldades e aspectos positivos no ensino da Educação Física na EJA.

\section{Cuidados Éticos}

Os entrevistados foram informados dos objetivos da pesquisa e assinaram o Termo de Consentimento Livre e Esclarecido, sendo mantido em absoluto sigilo os receptivos nomes. As escolas autorizaram o estudo mediante a assinatura da carta de anuência. Os nomes das escolas e dos professores não são divulgados. Para os professores, usam-se os códigos: professor 1, professora 2, professora 3 e professor 4 .

\section{DIFICULDADES E ASPECTOS POSITIVOS NO ENSINO DA EDUCAÇÃO FÍSICA NA EJA}

Nesta seçáo, são apresentados os resultados das entrevistas, com foco nas dificuldades relativas ao ensino da Educação Física na EJA e nos aspectos positivos. Em relação às dificuldades, o cansaço dos alunos nas aulas pelo fato de serem alunos trabalhadores é identificado nas falas dos professores abaixo:

"Os principais desafios são o fato de os alunos chegarem exaustos na aula, sendo para eles um terceiro turno" (Professor 1).

"Os alunos chegam muito exaustos da jornada de trabalho e muitas vezes preciso modificar o plano de aula devido ao cansaço desses estudantes" (Professora 2). 
A fala dos dois professores corrobora a característica dos alunos da EJA, de serem estudantes trabalhadores, apontada por Laffin (2012). Portanto, a EJA tem uma função social no sentido de ser reparadora de uma dívida social, ao propiciar condiçôes para que cidadãos brasileiros que não conseguiram estudar no período indicado possam concluir seus estudos. Sartori (2011, p. 14) destaca que se trata de "uma relação de produção e exclusão, que, infelizmente, ainda perdura na sociedade brasileira". Ainda podemos acrescentar que, frente ao contexto da pandemia de Covid-193, sabe-se que as classes mais pobres foram as que sofreram mais para conseguirem continuar estudando, principalmente, por não terem os recursos tecnológicos necessários para acompanhar as aulas mediadas pelas tecnologias ou por terem que trabalhar para auxiliar na renda familiar, o que leva muitos a se evadirem da escola.

No que se refere à Educação Física, há necessidade de ampliar a compreensão acerca do cansaço dos estudantes que frequentam as aulas no terceiro turno, após dois turnos extenuantes de trabalho. Nesse caso, a compreensão de Educação Física com foco apenas na aptidáo física, limitando-se apenas ao exercitar-se, não atende as necessidades desses alunos, uma vez que ela não é sinônimo de trabalho, nem se limita apenas a esforço físico.

Nesse sentido, González e Fensterseifer (2010) comentam que diversos estudos têm revelado que a Educaçáo Física entra na escola com o propósito de preparar o corpo e/ou, por meio do corpo, o caráter. Ainda, segundo os autores, a Educação Física é reconhecida, no aspecto legal, como componente curricular que abrange uma dimensão da cultura que tem responsabilidade com o conhecimento produzido, que vai muito além do "exercitar-se". Ou seja, a Educação Física deve tratar dos conhecimentos relativos: "a) às possibilidades de se movimentar dos seres humanos; b) às práticas corporais sistematizadas vinculadas ao campo do lazer e à promoçáo da saúde; c) às estruturas e representaçôes sociais que atravessam esse universo" (GONZÁLEZ; FENSTERSEIFER, 2010, p. 13).

Portanto, corroborando o pensamento dos autores, há necessidade de a Educação Física na EJA ampliar sua compreensão, trabalhando na perspectiva de uma Educação Física para o lazer e para a saúde. Günther et al. (2013, p. 21) reforçam que "experiências inovadoras realizadas em turmas de EJA têm atestado o interesse dos estudantes por uma EF para além da reprodução de práticas corporais restritas".

3 A pandemia ocasionada pelo Coronavírus teve como consequência o cancelamento, no Brasil, das aulas presenciais em todos os níveis de ensino, a partir de março de 2020. Essa medida foi adotada em virtude da recomendação da Organização Mundial da Saúde para evitar aglomeraçôes de pessoas, medida necessária para evitar a propagação do vírus. Consequentemente, as aulas presenciais ocorreram de forma remota e as tecnologias digitais, tais como ambientes virtuais de aprendizagens e as videoconferências, foram estratégias metodológicas utilizados pelas escolas. Contudo, o acesso aos equipamentos (computadores, celular...) assim como o acesso à internet foram necessários para acompanhar as aulas. 
Outra dificuldade evidenciada nas falas dos professores foram os problemas sociais dos alunos, que afetam diretamente a participação e a adesão dos alunos às aulas. Todos os professores se manifestaram nesse sentido:

"Quando vem da faculdade o professor chega motivado, quer colocar tudo em prática o que foi aprendido, mas se depara com uma realidade diferente que é a escola hoje, tornando-se um 'depósito' de problemas sociais enfrentados pelos alunos" (Professor $1)$.

"Muitos alunos têm problema de depressão e isso, muitas vezes, acaba alterando o plano de aula" (Professora 2).

"Os alunos têm diversos problemas sociais e muitos sequer têm uma alimentaçâo adequada o que interfere na aprendizagem dos estudantes e também há a desestrutura familiar" (Professora 3).

"Os alunos trazem diversos problemas sociais, principalmente relacionados à desestrutura familiar, o que acaba interferindo na aprendizagem dos alunos" (Professor 4).

Os problemas sociais mencionados pelos professores de Educação Física não afetam apenas as aulas de Educação Física. Há de se considerar que esses alunos carregam consigo uma história de vida, marcada por dificuldades que os impediram de concluir os estudos na idade recomendada. Dessa forma, há de se compreender também o esforço que esses alunos fazem para retornarem à escola e a esperança que depositam nela como possibilidade de terem uma vida melhor. Nesse sentido, a escola precisa acolher esses estudantes, para que não evadam novamente.

Por isso, Ostrovski e Correia (2018) ressaltam que a EJA merece atenção especial, pelo fato de desenvolver suas atividades com um grupo diferenciado de alunos, que não estudaram no período adequado à idade escolar. A maioria dos estudantes da EJA foi exposta a situaçóes complexas relacionadas às dificuldades financeiras, familiares, entre outras, o que levou ao abandono da escola. Portanto, os autores ressaltam a importância da EJA:

Então, deveria promover uma educação de qualidade e específica para esse público diferenciado, proporcionar maior conhecimento, ascensão profissional e, consequente, melhoria das condiçóes de vida pelo despertar como cidadáo crítico e consciente da realidade social (OSTROVSKI; CORREIA, 2018, p. 37).

Outra dificuldade é a diferença de faixa etária entre os alunos. Os professores mencionaram que os alunos têm entre 15 e 62 anos, o que dificulta, muitas vezes, a proposta das aulas, conforme evidenciamos na fala de três professores:

"A presença de alunos muito jovens no turno da noite não é produtivo, mas 'eles na parte do diurno são convidados a se retirar'e acabam se inserindo na EJA, não tendo interesse nenhum nas aulas, diferente dos alunos mais velhos que vão com o intuito de aprender" (Professora 2). 
"Os alunos mais novos teriam que frequentar as aulas no turno do diurno, para dar mais oportunidade para os trabalhadores que estão frequentando a EJA de forma muito reduzida" (Professora 3).

"Os alunos de mais idade não têm o mesmo entendimento dos fundamentos das modalidades, precisamos fazer trabalho em grupos para que esses alunos consigam chegar ao mesmo nivel dos demais" (Professor 4).

A análise das falas dos professores nos remetem a duas questôes. A primeira trata do deslocamento do aluno do diurno, marcado por um histórico de repetência e de desinteresse pelo estudo, que é induzido a ir para o ensino noturno, "convidado a ir para a EJA", assim que ele atinge a idade mínima. Contudo, deslocar o aluno do diurno para o noturno pode auxiliar o ensino diurno, mas transfere o problema para o outro turno, gerando dificuldades para o estudante da EJA, que retorna à escola e tem interesse em estudar.

A segunda questão, específica da Educação Física, diz respeito à maior habilidade técnica das modalidades, no caso esportivas, do aluno do diurno, ao contrário dos alunos com idade mais avançada. Percebe-se que essa diferença de habilidades é entendida como uma dificuldade pelo professor 4, cuja preocupação é que todos tenham o mesmo nível de habilidade. Porém, desejar que, na Educação Física da EJA, em que o grupo é heterogêneo, todos tenham o mesmo nível de habilidade não seria uma proposta inadequada? Ensinar a Educação Física tendo como principal objeto de ensino o esporte, que é competitivo, seria uma escolha correta?

Entendemos que uma Educação Física que trabalhe com a diversidade de práticas corporais para além dos esportes pode auxiliar no entendimento de o "nível" de habilidade ser um problema para as aulas. Como exemplo, citamos o trabalho com jogos cooperativos. De acordo com Alencar et al. (2019, p. 2019), "o professor necessita atentar-se em possibilitar as diversas manifestaçóes de conhecimento, não apenas focar nos jogos competitivos e nas modalidades esportivas em si, sendo os jogos cooperativos uma das estratégias eficazes que pode ser utilizada".

No contexto da Educaçáo Física, os jogos cooperativos, de maneira lúdica e prazerosa, são uma excelente estratégia de prática pedagógica. Por meio deles, é possível proporcionar conhecimentos a respeito da cultura corporal, bem como são um meio de inclusão e estímulo para pensar no outro, contribuindo assim com a formação do aluno para o convívio social. Contudo, é importante que façam parte da rotina escolar como um todo (ALENCAR et al., 2019). Além dos jogos cooperativos, também podemos acrescentar a dança, trabalhos de pesquisa sobre temas diversos tais como a relação entre exercício físico e saúde, atividades físicas ao ar livre, exercícios compensatórios para os alunos que trabalham com movimentos repetitivos, entre outras possibilidades.

Ainda, com relação ao fato de haver alunos de diferentes faixas etárias na sala de aula, ressalta-se que a intergeracionalidade é uma característica da EJA, que tem crescido com o aumento da migraçáo de adolescentes para essa modalidade de ensino. A intergeracionalidade, conforme Rabello (2011), propicia um processo 
de interaçóes sociais de indivíduos de idades distintas; porém, isso náo precisa ser entendido como uma dificuldade, mas como uma possibilidade de aprender com o outro. A característica essencial do homem é ser e estar sociável. A participação social está presente nos diversos momentos da vida humana. Na nossa trajetória, convivemos e aprendemos com diferentes pessoas e distintos grupos, seja na família, na escola, seja no trabalho, no lazer; até no momento da morte, a relação com o outro constitui um ritual de vínculo com o contexto social. Essas interaçôes induzem a transformar e a ser transformado, o que fundamenta a educação permanente. "A educaçáo permanente deve estar sempre voltada à realidade da vida. A experiência traz um interessante resultado, fazendo com que os alunos de diversas geraçóes, culturas e perfis construam sua própria aprendizagem" (RABELLO, 2011, p. 6364).

Quanto aos aspectos positivos são apontados três pelos professores: interesse dos estudantes pelas atividades desenvolvidas, contribuiçóes que as atividades proporcionam aos alunos e respaldo da escola para a realização das aulas.

A respeito do interesse pelas atividades desenvolvidas, o professor 1 comenta:

"O interesse dos alunos é altamente positivo, principalmente os mais velhos que acabam trazendo sua experiência aos mais novos e se engajam em aprender os fundamentos das modalidades" (Professor 1).

A fala acima remete ao entendimento de que a interageracionalidade é também apontada como um aspecto positivo. Nesse sentido, as trocas são potencializadoras de aprendizagens, que vão além dos objetos de conhecimento da Educação Física, que tratam da especificidade dos gestos motores e das técnicas esportivas. Os mais velhos compartilham a sua experiência de vida, mas também se esforçam para aprender as práticas corporais. Nesse sentido, Leal e Maciel (2014, p. 10) acentuam o papel da Educação Física na EJA:

Acredita-se que o acesso à cultura corporal de movimento é um direito do cidadão, uma perspectiva de construção e usufruto de instrumentos para promover a saúde, utilizar criativamente o tempo de lazer e expressar afetos e sentimentos em diversos contextos de sobrevivência. Ou seja, oportunizar a apropriaçáo dessa cultura pode e deve se constituir num instrumento de inserção social, de exercício da cidadania e de melhoria da qualidade de vida. Para que isso se concretize, cabe ao professor apreender os conhecimentos específicos da área e adequá-los à realidade discente.

Com relação às contribuiçôes da Educação Física para a formação dos alunos, na sequência, o relato de dois professores:

"Ter crescimento como cidadão no qual a Educação Física proporciona interação e socialização, os alunos podem se movimentar e ter conhecimento do corpo. Os exercícios fisicos acabam trazendo beneficios para o estudante diferente dos outros componentes no qual eles ficam sentado muito tempo" (professora 2).

"A EJA é importante para os alunos concluirem os estudos e terem novas oportunidades, superando as dificuldades que é aliar estudo com trabalho" (professor 4). 
Nas falas acima, percebe-se que a Educação Física contribuiu para a saúde dos alunos à medida que proporciona o movimentar-se. Porém, também se destaca a importância de o aluno estar na escola para sua formaçáo enquanto cidadáo, pois, através do estudo, consegue ampliar seus horizontes. Por isso, é relevante destacar a importância de os professores de Educação Física conseguirem olhar para os alunos da EJA para além da especificidade de seu componente, ou seja, é preciso compreender a essência da EJA. Segundo Günther et. al (2013), a EJA representa um esforço para corrigir as consequências da desigualdade social, através da oportunidade de concluir os estudos, ofertada a pessoas alijadas do processo de escolarização na infância e na adolescência.

Com relação ao respaldo da escola para o desenvolvimento das aulas de Educação Física, todos os professores destacaram que se sentem apoiados:

"A escola está sempre disponivel em colaborar, tendo diversos materiais e procurando respaldar os alunos com suas dificuldades em seu cotidiano" (professor 1).

"A contribuição da escola também vem consolidar um bom ambiente de trabalho, além de ter uma ótima estrutura, também respalda os alunos com as dificuldades no meio social, trazendo palestra e conversa com familiares" (professora 2).

"A escola está sempre disposta a contribuir com melhorias no ginásio, diversos materiais, tornando melhor a qualidade das aulas de educação física" (professora 3).

"A escola procura apoiar com materiais dentro do possivel. O fato de ainda não ter um ginásio coberto traz algumas dificuldades para a execução das aulas nos dias de chuvas" (Professor 4).

Nas falas dos professores, dois aspectos sobressaem. Um deles trata das necessidades físicas e materiais para desenvolver boas aulas. $\mathrm{O}$ outro remete às açóes da escola para abordar temas relacionados às dificuldades cotidianas dos alunos, entre elas, as sociais, que dizem respeito ao desemprego, à desestrutura familiar, à drogadiçáo, já apontadas anteriormente pelos professores. Portanto, constata-se que a escola se preocupa com o aluno, com os fatores que afetam a sua permanência na escola e com suas aprendizagens e busca dar suporte aos professores para que consigam desenvolver o seu trabalho. Mas, além disso, espera-se contribuir para fechar a ferida aberta, como mencionam Günther et al. (2013), que diz respeito, no nosso sistema de ensino, à necessidade de adolescentes e adultos recorrerem à EJA, após sucessivas repetências, para finalizar seus estudos de forma mais rápida.

\section{CONSIDERAÇÓES FINAIS}

Este estudo teve como objetivo conhecer as dificuldades e aspectos positivos no ensino da Educação Física na EJA, a partir da percepção de professores de Educação Física.

Constatou-se que, na Educação Física, no tocante a fatores externos à escola, os principais desafios são os problemas sociais que interferem na aprendizagem dos estudantes e na sua permanência na escola. Outro problema é o fato de muitos 
alunos chegarem exaustos ao terceiro turno, situação que impóe a revisão do planejamento para que haja adesão dos alunos às aulas.

Contudo, uma dificuldade apontada emerge da própria escola. Ela diz respeito ao deslocamento para a EJA de estudantes mais jovens que foram "convidados" a deixar o ensino diurno. Porém, na EJA, esses jovens também não se engajam nas aulas, gerando dificuldades aos professores de Educaçáo Física e aos alunos mais velhos que retornaram à escola e querem estudar.

Quanto aos aspectos positivos, destaca-se o engajamento dos alunos nas aulas. Mesmo os mais velhos esforçam-se para aprender as práticas corporais com as quais não têm familiaridade. Ainda, percebem-se aprendizagens voltadas para a cidadania e para a saúde. Todos os professores destacam que recebem apoio da escola para o desenvolvimento de suas aulas, sejam condiçóes físicas e materiais ou ao abordarem temas relacionados aos problemas sociais dos estudantes.

A partir das evidências da pesquisa, reforçamos a necessidade de que a Educação Física na EJA olhe e acolha a diversidade que caracteriza os alunos. Todos, de uma forma ou de outra, foram excluídos da escola em algum momento. Portanto, a Educação Física precisa romper com a visão que se ampara no desenvolvimento da aptidão física ou esportiva e ampliar as suas açóes reconhecendo que cada aluno da EJA tem uma história de vida singular. A Educaçáo Física, junto com os demais componentes curriculares, deve assumir o compromisso social de auxiliar esses alunos a realizarem seu sonho de concluir os estudos, o que náo foi possível no tempo adequado.

Por fim, como sugestáo de continuidade da pesquisa, sugere-se investigar junto aos alunos da EJA como eles compreendem a relevância da Educação Física para a sua formação.

\section{REFERÊNCIAS}

ALENCAR, G. P. de; PEREIRA, M. da G. de L.; PEREIRA, T. T.; OLIVEIRA, C. M. V. de; MORAIS, C. S. de; OTA, G. E. Jogos Cooperativos: Relaçóes e Importância na Educação Física Escolar. Revista de Ensino, Educaçáo e Ciências Humanas. v. 20, n. 2, p. 220-223, 2019. DOI: http://dx.doi.org/10.17921/2447-8733.2019v20n2p220-223

BOGDAN, R.; BIKLEN, S. Investigaçáo qualitativa em educaçáo: uma introdução à teoria e aos métodos. Porto: Porto Editora, 1994.

BRASIL. Parecer CNE/CEB 11/2000 - Homologado. Disponível em: http://portal.mec. gov.br/secad/arquivos/pdf/eja/legislacao/parecer_11_2000.pdf. Acesso em: 06 dez. 2021.

. Lei n. ${ }^{\circ} \mathbf{1 0 . 7 9 3}$, de $\mathbf{1}^{\circ}$ de dezembro de 2003 . Altera a redaçáo do art. $26, \$ 3^{\circ}$, e do art. 92 da Lei n. ${ }^{\circ}$ 9.394, de 20 de dezembro de 1996, que "estabelece as diretrizes e bases da educação nacional", e dá outras providências. Disponível em: http://www. planalto.gov.br/ccivil_03/leis/2003/110.793.htm. Acesso em: 19 set. 2021. 
Lei n.o 9394 de Diretrizes e Bases da Educaçáo Nacional, de 20 dezembro de 1996. Estabelece as diretrizes e bases da educação nacional. Disponível em: http://www. planalto.gov.br/ccivil_03/Leis/L9394.htm. Acesso em: 10 mai. 2019.

Lei n.` 10.793 de 2003. Altera a redação do art. 26, $₫$ 3o, e do art. 92 da Lei no 9.394, de 20 de dezembro de 1996, que "estabelece as diretrizes e bases da educação nacional”, e dá outras providências. Disponível em: http://www.planalto.gov.br/ccivil_03/ leis/2003/L10.793.htm. Acesso em: 03 jun. 2019.

. Lei n.o 13.632, de 2018. Altera a Lei no 9.394, de 20 de dezembro de 1996 (Lei de Diretrizes e Bases da Educação Nacional), para dispor sobre educação e aprendizagem ao longo da vida. Disponível em: https://www2.camara.leg.br/legin/fed/lei/2018/lei13632-6-marco-2018-786231-publicacaooriginal-154957-pl.html. Acesso em: 10 mai. 2019.

Ministério da Educação. Base Nacional Comum Curricular (BNCC). O ensino fundamental no contexto da educação básica. Brasília, 2017. Disponível em: http:// basenacionalcomum.mec.gov.br/abase/\#fundamental. Acesso em: 30 abr. 2021.

Lei no 13.632, de 6 de março de 2018. Altera a Lei no 9.394, de 20 de dezembro de 1996 (Lei de Diretrizes e Bases da Educação Nacional), para dispor sobre educação e aprendizagem ao longo da vida. Disponível em: http:/www.planalto.gov.br/ ccivil_03/_ato2015-2018/2018/lei/L13632.htm. Acesso em: 19 de set. 2021.

Resoluçáo n. ${ }^{\circ}$ 1, de 28 de maio de 2021. Institui diretrizes operacionais para

a Educação de Jovens e Adultos nos aspectos relativos ao seu alinhamento à Política Nacional de Alfabetização (PNA) e à Base Nacional Comum Curricular (BNCC), e Educação de Jovens e Adultos à distância. Disponível em: https://www.in.gov.br/en/web/ dou/-/resolucao-n-1-de-28-de-maio-de-2021-323283442. Acesso em: 19 set. 2021.

CARVALHO, R. M. (Org.). Educação física escolar na educação de jovens e adultos. Curitiba: CRV, 2011.

GONZÁLEZ, F. J.; FENSTERSEIFER, P. E. Entre o "Não mais" e o "Ainda não":

Pensando saídas do não lugar da escola II. Cadernos de Formaçáo RBCE. Campinas:

CBCE e Autores Associados, p. 10-21, mar., 2010.

GÜNTHER, M. C.; SILVA, G. N. da; PAIM, A. dos S.; OJEDA, T.R. A Educação

Física na educação de jovens e adultos. Lajeado, 2013. Anais... Lajeado: Univates, 2013. E-book. Disponível em: https://www.univates.br/editora-univates/media/publicacoes/47/ pdf_47.pdf. Acesso em: 19 jan. 2021.

LAFFIN, M. H. L. F. (Org). Educação de jovens e adultos e educação na diversidade. Florianópolis: UFSC, 2011.

A constituição da docência entre professores de escolarização inicial e jovens e adultos. Ijuí: Unijuí, 2012. 
LEAL, M. B.; MACIEL, R. R. A. Os desafios das práticas pedagógicas da Educação Física no Proeja. Do Corpo: ciências e artes. Caxias do Sul, v. 4, n. 1, p. 1-11, 2014. Disponível em: http://www.ucs.com.br/etc/revistas/index.php/docorpo/article/ view/3448/2007. Acesso em: 19 de set. 2021.

MORAES, R.; GALIAZZI, M. do C. Análise textual discursiva: 3 ed. Ijuí: Unijuí: 2016.

NEGRINE, A. Instrumentos de coleta de informaçóes na pesquisa qualitativa. In: MOLINA NETO, V.; TRIVIÑOS (Org.). A pesquisa qualitativa na Educaçáo Física. Porto Alegre: Sulina, 1999. p. 61-94.

OSTROVSKI, C. S.; CORREIA, Z. D. Educação de jovens e adultos e a evasão escolar: análise e proposição. Educação: Teoria e Prática, v. 28, n. 57, p. 23-40, 2 maio 2018. DOI: http://dx.doi.org/10.18675/1981

RABELLO, Sandra. Desigualdade social, longevidade, juventude idosa e a intergeracionalidade. In: CARVALHO, Rosa Malena (Org). Educaçáo física escolar na educaçáo de jovens e adultos. Curitiba: CRV, 2011. p. 59-69.

SARTORI, A. Legislação, Políticas Públicas e Concepções de Educação de Jovens e Adultos. In: LAFFIN, M. H. L. F. (Org). Educaçáo de jovens e adultos e educaçáo na diversidade. Florianópolis: UFSC, 2011. p. 12-125.

SOUZA, M. A. de. Educação de jovens e adultos. Curitiba: Intersaberes, 2012.

TRIVIÑOS, A. N. Introduçáo à pesquisa em ciências sociais: a pesquisa qualitativa em educação. São Paulo: Atlas. 1987. 